\title{
Orientalismos americanistas: Vicente Fidel López, Francisco Adolfo de Varnhagen y los indígenas
}

\author{
João Paulo Coelho de Souza Rodrigues \\ Universidade Federal de São João del Rei \\ jprodrigues@ufsj.edu.br
}

Recepción: 3 de enero de 2013 / Revisión: 21 de abril de 2013

Aceptación: 15 de mayo de 2013 / Publicación: diciembre de 2013

\begin{abstract}
RESUMEN
Este artículo examina las teorías acerca de los orígenes de los indígenas tupís, de Francisco Adolfo de Varnhagen, y de los indígenas peruanos, de Vicente Fidel López. Se propone que la deriva historicista de esas teorías se debía a los aportes lingüísticos del orientalismo. El objetivo de este trabajo es arrojar luz sobre las relaciones, en ambos autores, entre indigenismo, lingüística, historiografía y proyectos políticos para Argentina y Brasil.
\end{abstract}

Palabras clave: indigenismo, lingüística, historicismo, Argentina, Brasil, siglo XIX.

\section{Americanists Orientalisms: Vicente Fidel López, Francisco Adolfo de Varnhagen and the Indians}

\begin{abstract}
This article analyzes Francisco Adolfo de Varnhagen's and Vicente Fidel López' respective theories on the origins of the Tupi and Peruvian Indians. In particular, it puts forward that the historicist approach of the authors' theories can be attributed to the linguistic contributions of orientalism. The principal aim of this work is to shed light on the connections, in both authors' works, between indigenism, linguistics, historiography and political plans for Argentina and Brazil.
\end{abstract}

Key words: Indigenism, Linguistics, Historicism, Argentina, Brazil, 19th Century.

Sumario: 1. Los orientalismos. 2. El problema del origen de los indígenas. 3. El quechua y el tupí en López y en Varnhagen. 4. Perspectivas políticas de López y de Varnhagen. 5. ¿Varnhagen lector de López? 6. Conclusión. 7. Referencias bibliográficas. 
En los numerosos trabajos sobre la historia intelectual del siglo XIX no existe controversia en torno de la afirmación de que la revolución historicista iniciada en el siglo anterior con la Ilustración cobra cuerpo, haciéndose hegemónica ${ }^{1}$. El cambio intelectual, tal como se divulga en esos trabajos, tuvo como principal responsable la disciplina que precisamente tomaba como título el término que identificaba estas nuevas nociones de la relación entre tiempo, cambio, individuo y sociedad: la historia. La dirección histórica se impuso en las letras y en las ciencias, lo que explica en buena medida los vasos comunicantes entre ellas. Por ese prisma, se convierte en materia de investigación el diálogo que la historiografía decimonónica mantenía con otras disciplinas. En parte, los estudios recientes sobre la importancia de la novela romántica, del folclore y de la etnología responden a parte del interrogante. Sin embargo, poco se ha estudiado la influencia o la recepción que algunas ciencias más apartadas tuvieron en el desarrollo de la historiografía, en particular una de las más impactantes: la lingüística.

\section{LOS ORIENTALISMOS}

Antes que la historia intelectual se interesara por la historiografía decimonónica, Hobsbawm ya había destacado que el sentido histórico estaba presente en varios campos, y notó que la primera ciencia cuyo objeto de estudio se fundaba en leyes "fundamentalmente históricas" ${ }^{2}$ fue, precisamente, la lingüística que, con su método descriptivo y comparativo, pudo establecer algunas lenguas en una cadena de transformaciones, clasificándolas en grupos genealógicos. Desde su origen (fines del siglo XVIII), presentaba también una historia de las civilizaciones, lo que no pasó desapercibido entre los letrados sudamericanos. El argentino Vicente Fidel López $z^{3}$, por ejemplo, escribiría "que el parentesco de lengua, de religión, de tradición, es suficiente para probar el origen común de las naciones europeas"4. Un poco antes, su compatriota Domingo Sarmiento destacaba el papel que tenían "la filología y las inscripciones descifradas" en el progreso de la historiografia ${ }^{5}$. El miembro del Instituto Histórico e Geográfico Brasileiro, Ernesto França, mantenía el mismo juicio al destacar la importancia del estudio de las lenguas americanas como subsidiario de la historia, ciencia que cambiaba "la apreciación teórica y práctica de los acontecimientos políticos"6.

\footnotetext{
1 Agradezco a Charles Jones, Luiz Francisco de Miranda, Ori Preuss y Juan Pablo Scarfi las sugerencias bibliográficas y discusiones de tópicos contenidos en el artículo. Además, Scarfi gentilmente corrigió el castellano del autor. Agradezco también a los evaluadores de la Revista Complutense de Historia de América por sus comentarios a la primera versión de este artículo.

2 Hobsbawm, 1991, p. 263.

3 Buenos Aires, 1815-Buenos Aires, 1903. De una de los más importantes linajes intelectuales y políticos de Argentina del siglo XIX, era hijo del autor del himno nacional, hombre político y juez, Vicente López y Planes (1785-1856). Vicente Fidel López fue abogado, economista, historiador, jurista, lingüista, novelista, profesor, editor de la Revista del Río de la Plata, rector de la Universidad de Buenos Aires (1874-1877), diputado nacional (1876-1879) y ministro de la Hacienda (1890-1892). Vivió exiliado en Chile (1840-1852) y en Montevideo (1853-1871). Su hijo, Lucio Vicente López (1848-1894) fue periodista, escritor y político. Para mayores detalles, véase al artículo del Dr. Charles Jones en el presente dossier.

4 LÓPEZ, $1871 \mathrm{a}$, p. 314.

5 SARMiEnto, 1867a, p. 48. La ortografía fue actualizada.

6 FrançA, 1859, pp. IX-X. Todas las traducciones en el presente artículo son del autor del mismo.
} 
La lingüística puso al Oriente -sobre todo a la India- de moda. El orientalismo se hizo sentir en La Plata, particularmente en la peña de Sarmiento ${ }^{7}$. Otros miembros del grupo de exiliados liberales y románticos del régimen de Juan Manuel de Rosas, la generación de 1837, de la cual formaba parte Vicente Fidel López, adoptaron las representaciones sobre el Oriente y recurrieron al imaginario oriental para entender las instituciones políticas y las estructuras sociales de la Argentina. Como señala Adriana Amante, se presenta en ese grupo una "actitud" orientalista, a la vez que el Oriente no es una experiencia, sino un conjunto de referencias sacadas de lo que se ha leído, lo que, sin embargo, da sentido a lo que se ve ${ }^{8}$. Las referencias orientales se dirigen no solamente al mundo árabe, sino, más sintomáticamente, a la Argentina y a España. Amante -como otros- sigue el concepto de orientalismo elaborado por Edward Said: un discurso occidental despreciativo acerca de un inventado Oriente que justifica los proyectos imperiales europeos ${ }^{9}$.

El orientalismo también se hizo sentir en Brasil. Sin embargo, su aspecto no comportaría, en su primer momento, un exotismo despreciativo, como atesta la carta, probablemente de 1838, de Raimundo José da Cunha Matos al Instituto Histórico e Geográfico Brasileiro, acerca de la historia nacional. Para Matos, la primera época (de los "aborígenes o autóctonos") era la más difícil de definir, por "falta de monumentos bíblicos o lapidares que sirvan al menos para dar un cierto color de probabilidad a nuestras conjeturas" 10 . La ciencia desarrollada por el orientalismo se presentaba en la demanda por la elaboración de un árbol genealógico que respondiera a esa imposibilidad, pues sólo la lingüística conseguiría descubrir el origen de los nativos americanos. Había, todavía, un problema: los tupís y las otras "naciones" no dejaron "monumentos" conocidos en los cuales se pudieran leer jeroglíficos. El Instituto Histórico recibía noticias de ruinas en el interior del país, que debían ser investigadas. Matos revivía sus esperanzas, por lo tanto, en la posibilidad del descubrimiento de "piedras" o "láminas", en una repetición de lo ocurrido con la egiptología a partir de Champollion, quien publicara su trabajo un poco antes, en 1822. La amplia dimensión del orientalismo como paradigma lingüístico, etnográfico, arqueológico y, por todo eso, histórico, se revela en los "admirables edificios [de indígenas centro-americanos] cuyas ruinas majestuosas hoy se estudian, y se asemejan a las del antiguo Egipto y las de diferentes pueblos del Indostán y de la Asia occidental"11.

No fue sólo en América que el orientalismo contenía varios matices y puntos geográficos de referencia. En realidad, desde el principio hubo varios orientalismos, y el

\footnotetext{
7 Altamirano, 1994; Colombi, 2005; Roldán, 2005; Gasquet, 2007.

8 Amante, 2005. Véase también: Cicerchia, 2004 y Gasquet, 2007. El orientalismo en la cultura argentina no se queda circunscripto al siglo XIX, como destacan TAUB, 2008 y GasQuet, 2007.

9 SAID, 1990.

10 Matos, 1863, p. 129. Es curioso notar que para los letrados criollos de otras partes y de algunas décadas anteriores, como en Guatemala y México entre 1780 y 1820, la presencia de ruinas y jeroglíficos no disminuye los interrogantes sobre la historia antigua de América, aunque se creyera que fueran esenciales como documentos históricos (CASANOVA, 1994).

11 Ibídem, p. 140. El autor probablemente se refería a Palenque, en Chiapas, descubierta en 1784 y divulgada en 1822, y que causó gran impacto en Europa. Sobre ese asunto, véase: CASANOVA, 1994. En 1835, esas ruinas mayas llamaron la atención del diplomático brasileño Ponte Ribeiro, quien se admiró de la "perfección de las figuras en bajo relieve" del conjunto arquitectónico. Ribeiro, 2012, p. 103.
} 
cuadro negativo de Said llevó a que solamente uno de los sentidos haya sido adoptado por los historiadores. El orientalismo saidiano deriva de un análisis de la pintura y de la literatura de la Francia y la Inglaterra decimonónicas que retrataban el Levante y el norte de África. No era la única vertiente, y tampoco la más representativa, pues, como señala Thomas Trautmann ${ }^{12}$, el vínculo que el crítico literario palestino establece entre discurso e imperialismo no da cuenta del papel de los sabios alemanes en la difusión de la indomanía. Tampoco explica la representación orientalizada de España por el romanticismo anglo-francés, que influenció a los escritores argentinos y también algunos españoles ${ }^{13}$. Se puede añadir que al privilegiar las representaciones literarias, Said las convierte en una disciplina orientalista sin distinción con el orientalismo como investigación erudita, perspectiva que es seguida por los críticos y historiadores que estudiaron el orientalismo argentino, el cual estuvo hecho en casi su totalidad de aportes literarios. Trautmann nota, por ejemplo, que el argumento foucaultiano del vínculo entre saber y poder entra en contradicción cuando los ejemplos más significativos destacados por Said son de autores que no conocían una o más lenguas de África o de Asia, condición necesaria para quien quisiera dedicarse al estudio del "Oriente".

Si uno se aparta de un orientalismo unidimensional, imperialista y restringido al universo árabe, percibe que varios Orientes surgen como referencia. La historia intelectual de la América del Sur en el ochocientos presenta casos de empatía, como el de Vicente Fidel López. El mismo Sarmiento escribe, no sin su habitual exageración retórica, que el idioma español, vehículo de un pueblo europeo decadente, estaba destinado a desaparecer por no expresar ideas progresistas y un destino similar tuvieron el latín, el griego, el hebreo y el sánscrito, que, todavía, "valían y sirvieron más que" el español ${ }^{14}$. El sentido dado por Said no explica la atracción de la monarquía brasileña por el Egipto, expresada en la adquisición de reliquias y momias para el Museo Imperial, desde fecha tan temprana como 1827 -apenas cinco años después de la independencia. Don Pedro II, además, estudió hebreo, árabe y egipcio, mantuvo correspondencia con el egiptólogo Heinrich Karl Brugsch y visitó dos veces la patria de las pirámides. Se debe notar que después de la expedición de Napoleón Bonaparte, hubo una "egiptomania" en Europa y en Estados Unidos ${ }^{15}$.

\section{EL PROBLEMA DEL ORIGEN DE LOS INDÍGENAS}

En el siglo XIX, tanto en Europa como en América, el interés por la historia se desarrolló en estrecho vínculo con instituciones estatales. En el caso hispánico, en paralelo con las reformas borbónicas de la administración del imperio de la segunda mitad del siglo XVIII, el gobierno monárquico estimuló las expediciones arqueológicas, la colección de artefactos y manuscritos indígenas de México, Perú y América Central y el desarrollo de sociedades de hombres ilustrados en las capitales virreinales o de

\footnotetext{
12 Trautmann, 1997, pp. 19-26.

13 JunCO, 2003, pp. 200, 204, 246 y 256.

14 Sarmiento, 1867 b, p. 70. La ortografía fue actualizada.

15 Aurenche, 2003.
} 
capitanías americanas. Con ese nuevo estímulo, el interrogante sobre el origen de los indígenas cobró cuerpo. En el siglo XVI, los cronistas de la conquista habían indicado semejanzas entre los nativos, por un lado, y los moros y judíos, por otro ${ }^{16}$. El tema volvió a ser objeto de conjeturas entre los letrados criollos y españoles, los primeros estimulados por un patriotismo aún no independentista. Sin embargo, se desarrolló un interés por la grandiosidad de la historia antigua del Nuevo Mundo, que fue relacionada con la clásica. Se conjeturó sobre la presencia de fenicios, egipcios y romanos en la construcción de las ciudades aztecas y mayas, principalmente ${ }^{17}$. El interés por el tema de parte de las nuevas naciones formadas en el continente a partir de la invasión napoleónica de la península ibérica en 1808 fue muy marginal hasta mediados del siglo. No obstante, no desapareció en Europa, impresionada con la obra de Alexander von Humboldt, y recobró fuerza con los relatos de viajeros y, en el caso de México, con la invasión francesa de $1862^{18}$.

No circunscrita a la historiografía, como ya he señalado, la pasión oficialista por el pasado se reveló también en la simbología de los monumentos públicos y en las artes plásticas. En la pintura, por ejemplo, el indígena se destacó en el tema de la conquista, particularmente en Brasil y España, pero también en México y Perú. En todos esos casos la pintura histórica referida al encuentro entre indígenas y europeos tuvo significativo aporte estatal, constituyendo parte de lo que Reyero llamó "cultura de carácter oficialista" ${ }^{19}$.

Dos de los "padres fundadores" de las historiografías de Argentina y Brasil, respectivamente, Vicente Fidel López y Francisco Adolfo de Varnhagen ${ }^{20}$, se destacan en el eje que vincula la historia, la lingüística y el Oriente. López estuvo vinculado a la generación de 37, que entendía como tarea política fundamental conceder a Argentina unidad nacional y principios políticos liberales, en un marco de estabilidad institucional que superase el pasado colonial. Posteriormente a la caída de Juan Manuel de Rosas compartió con algunos contemporáneos (Juan María Gutiérrez, Bartolomé Mitre) las inquietudes por la elaboración de una historia nacional. Varnhagen, al contrario de la mayoría de los primeros letrados brasileños, que circulaban por la poesía,

16 SouZa, 2010, pp. 156-170.

17 Casanova, 1994.

18 Riviale, 1999.

19 Reyero, 2004, p. 723. Véase también Junco, 2003. Christo, 2009, p. 1158, comenta que mientras la pintura histórica mexicana posterior a la década de 1860 representaba al azteca estéticamente próximo al modelo clásico, sobresaliendo cuadros sobre el pasado pre-colombiano, la pintura histórica brasileña del mismo período presentaba al indígena en cuadros que tematizaban el primer contacto con los portugueses (donde eran los conquistadores el principal actor), o en cuadros alegóricos, sin fecha o lugar histórico definido, limitando al indígena a un tiempo mítico. Se puede añadir que en el aspecto del contacto y posición del colonizador, la pintura brasileña presenta similitudes con la pintura histórica española. Sobre la pintura histórica mexicana del siglo XIX, véase FLORESCANO, 2005 y RAMírez, 2003a y 2003 b.

20 São João de Ipanema, 1816-Viena, 1878. Hijo de un ingeniero militar alemán, estudió en colegios militares portugueses (1825-1833) y se graduó en la Real Academia de Fortificación, Artillería y Diseño de Lisboa (1839), después de luchar en la guerra civil portuguesa (1828-1834) al lado de los liberales. Por esa época hizo sus primeras investigaciones en los archivos portugueses, iniciando su obra historiográfica, prácticamente toda dedicada a la historia colonial de Brasil. Fue socio del Instituto Histórico y Geográfico Brasileño y diplomático, viviendo fuera de Brasil (en Asunción de Paraguay, Caracas, Lima, Lisboa, Madrid, Valparaíso y Viena), salvo por breves períodos, desde 1844 hasta su muerte. Fue agraciado por el Imperador Pedro II con el titulo de Vizconde de Porto Seguro en 1874. 
el periodismo político y el profesorado, eligió desde sus primeros años en las letras la historiografía. Todavía, como sus colegas, demostró interés en la cuestión indigenista, una de las pocas que le llevó a enunciar posiciones políticas. Esos dos letrados, en momentos distintos de sus respectivas trayectorias intelectuales y con distancia de pocos años, elaboraron teorías heterodoxas sobre el origen de los indígenas americanos a partir de datos lingüísticos. En efecto, representan dos originales apropiaciones del orientalismo, al mismo tiempo que ambiciosas tentativas de proyección científica internacional.

Los historiadores, lingüistas y científicos brasileños y europeos se interrogaban acerca de la llegada de pueblos de África, Asia o Europa a América - en particular a su parte meridional. Ya en el primer volumen de la revista del Instituto Histórico, los dirigentes de la asociación oficial de historia del joven Imperio se entusiasmaban con la posibilidad de que la nación participara no solamente en la investigación de la historia antigua del hombre, sino de que hubiese formado parte de la misma. Se publicó, en aquel número, un informe sobre presuntas inscripciones fenicias en un cerro en los alrededores de la ciudad de Río de Janeiro:

El descubrimiento de una inscripción es un hecho, que puede hacer una revolución en la historia; que puede reconquistar ideas perdidas, y aniquilar otras en pleno dominio: un nombre, una frase en una lápida, pueden llenar inmensos blancos, restaurando conjeturas, y abrir una estrada luminosa del pasado al futuro ${ }^{21}$.

Los autores no podrían resumir de manera más elocuente la fascinación que los estudios lingüísticos orientalistas estaban generando. A pesar de que afirmaran que los surcos en nada se parecían con los caracteres antiguos, declararon que no dejaban de tener fe en el descubrimiento de monumentos, ni de tener esperanza de ver aparecer "un Champoleon [sic] brasileño, ese Newton de la Antigüedad egipcia" 22 . Esa esperanza alimentó el duradero mito de ciudades perdidas y de inscripciones fenicias en el Brasil de la decimonovena centuria ${ }^{23}$.

Sin embargo, en el contexto de mediados del siglo XIX, la perspectiva de un vínculo de Brasil con el Oriente tenía otra connotación. Incluso Varnhagen, quien no sería el más benevolente respecto de los indígenas, ni el más entusiasta en cuanto a las ciudades perdidas, no dejaba de alertar a sus colegas letrados de que

conviene que estemos todos persuadidos de que nuestro pasado, el actual imperio mismo, interesará tanto más a las naciones civilizadas e instruidas cuanto más lejos pudiéramos hacer remontar, no las fuentes de nuestra historia, mas los mitos de sus tiempos heroicos, mas las inspiraciones de su poesía ${ }^{24}$.

La contradicción entre afirmar la importancia de la cuestión del origen de los tupís para el pasado de la nación y negarles participación en su formación, se mantiene en

\footnotetext{
21 Alegre y Barbosa, 1839, p. 77.

22 Ibídem, p. 80.

23 LANGer, 2002; Freitas, 2002, pp. 204-209.

24 VARnhagen, 1849, p. 370.
} 
toda su obra posterior ${ }^{25}$. El nativo vuelve, todavía, de manera incómoda, pues no puede fácilmente -en tiempos de historicismo romántico- ser excluido. En su magnum opus sobre los orígenes de los tupís ${ }^{26}$ se dice que su idioma, por más decaído que se encuentre, es hablado por toda la extensión del Imperio, comentarios reforzados por el reclamo de una política indigenista dura que sólo revelaba cómo el destino nacional (punto de anclaje del lineamento historicista) dependía del salvaje. Varnhagen no está ajeno a la perspectiva romántica de la nación como un ente cuya historicidad tiene que volver hasta tiempos remotos. Al mismo tiempo, si los tupís tienen un estatuto inferior en la historia colonial e independiente, son compensados con un alargamiento de su importancia en la etapa anterior, que deja de pertenecer solamente a Brasil.

Varnhagen representa un caso de seducción que los comienzos envueltos en brumas tienden a ejercer sobre los letrados brasileños del siglo XIX, en especial el heroísmo de los antiguos. Su estilo sobrio es tomado tres veces en su obra por una analogía mitológica clásica que involucra aspectos contradictorios, al afirmar que los tupís son "los Jasones de nuestra mitología, son los Fenicios de nuestra historia antigua, son nuestros invasores normandos en tiempos bárbaros" 27 . La frase es reproducida en la introducción de El origen turaniano de los americanos tupí-caribes ${ }^{28}$, y se remonta a otro argumento, desarrollado anteriormente en un artículo, que vinculaba a los tupís solamente con Amazonia, no con toda la nación: "los antiguos Normandos de este territorio, los Jasones y Argonautas de su mitología" 29 . La tentativa en la obra de Varnhagen de alejar a los tupís de la historia nacional va de la mano de la repetición de una analogía que revela su persistencia, aunque limitada a la historia antigua.

Varnhagen camina por la misma tenue línea que varios autores argentinos y brasileños, separando la perspectiva clasicista de la romántica. La tentativa revela la tensión en torno al tema del nativo en la historia nacional, que, al mismo tiempo, nunca estaba aislada de consideraciones historicistas más extensas en sus horizontes. Es sintomático, por lo tanto, que Varnhagen haga otro movimiento, que exalta la historia de los tupís al afirmar la existencia de palabras griegas, fuerte indicio de que esa última lengua fuera el cario ${ }^{30}$, lo que haría de aquel idioma americano una herramienta explicativa "de la historia antigua del Mediterráneo" 31 . A pesar de su original indigenofobia, Varnhagen termina por valorar a los tupís de un modo que no es posible detectar en otros autores mucho más benevolentes respecto de los indígenas, salvo, en parte, en las novelas de José de Alencar (O Guarani, 1856, e Iracema, 1865). Los tupís dejan de ser hombres de la prehistoria para convertirse en un pueblo varonil y conquistador de la Antigüedad clásica (aunque salvaje). Es así que Brasil es insertado, en retrospectiva y a través de los indígenas, en la historia universal.

25 Para la interpretación de que Varnhagen excluye totalmente al indígena de la historia nacional, véase: Turin, 2010. Para la opinión de que el Instituto Histórico y Varnhagen construyen la idea de un "indígena brasileño", presente en los principios de la historia nacional, mas ausente de su posterior desarrollo, véase: KODAMA, 2009.

26 VARNHAGEN, 1876.

27 VARnhagen, 1854, p. 106.

28 VARnhagen, 1876, p. VII (nota de pie de página).

29 VARNHAGEN, 1849, p. 373.

30 VARNHAGEN, 1876, p. 75.

31 Ibídem, p. 76. 
En efecto, Varnhagen nunca los alejará completamente de la historia nacional, pues nunca consiguió superar los parámetros de la historia universal y de la filosofía de la historia, intentando articularlos en una narrativa que estuviera al servicio tanto del agrandamiento del Imperio así como también del suyo propio. Por vía de los tupís, el territorio nacional era proyectado pasado adentro, prefigurando en miles de años al dominio bragantino de los Pedros y preparando el terreno a una segunda y definitiva proyección de la civilización del Viejo Mundo sobre el Nuevo Mundo. Por vía del descubrimiento de esa historia de ancianos vínculos entre América y el Mediterráneo, Varnhagen se posicionaba en un mismo nivel que los orientalistas que habían verificado los vínculos existentes entre Asia y Europa. De ahí el peculiar orientalismo y la utilización de la lingüística que sustenta su ambigua evaluación de los tupís.

Varnhagen, Barbosa, Matos y otros podían investigar y discutir esos temas porque tenían un sustancial apoyo institucional. Al mismo tiempo, la cuestión sobre los orígenes de los indígenas era también una cuestión sobre su grado de civilización, lo que, en el contexto de las primeras décadas de vida independiente, tenía un fuerte eco político en una nación bajo presión inglesa para terminar con el tráfico de esclavos africanos. En ese sentido, el indigenismo reflexionaba acerca de la posibilidad de la integración del indígena como trabajador civilizado, contexto en que surgió una de las vertientes del romanticismo literario de mediados del siglo XIX, el llamado "indianismo", en el cual se destacaron escritores como Domingos José Gonçalves de Magalhães, Antônio Gonçalves Dias, y José de Alencar, entre otros.

No se verificaría lo mismo en la región del Río de la Plata, lo que no significa que no hubiera interés por el nativo. ${ }^{32} \mathrm{El}$ intelectual orgánico de Rosas, Pedro de Angelis, fue un ávido coleccionista de documentos sobre los nativos y reconstruyó varios vocabularios indígenas ${ }^{33}$. Rosas comandó, entre 1832 y 1833, una campaña contra los nativos del sur, incorporando territorios desde la pampa hasta la provincia de Buenos Aires. Sin embargo, hizo varios tratados de paz con ellos, medida que sería repetida por los gobernadores de la provincia y por algunos presidentes de la república posteriores, hasta la "Conquista del Desierto" patagónico de 1879-1881. Como en Brasil, la política para los indígenas estaba involucrada en la cuestión del control del territorio nacional, que tenía un componente económico en la apropiación de la tierra. Faltaba el elemento de la mano de obra y la perspectiva de los gobiernos argentinos era la del tratamiento de un enemigo. En el discurso y en la letra de las leyes brasileñas -en contraste- se procuraba integrarlo bajo medidas paternalistas. En el Río de la Plata, al contrario de Brasil, no se desarrolló bajo el romanticismo un interés por el indígena, con la excepción del poema épico La cautiva (1837), de Esteban Echeverría. El tema volvería apenas en las novelas y relatos concernientes a la incorporación del territorio patagónico. Ese "indianismo", si se puede adoptar tal

32 En ese sentido, el caso mexicano, donde un pasado indígena monumental que justamente en el siglo XIX volvía a intrigar a la arqueología europea y norte-americana, ofrece un contraste interesante con Argentina. Asimismo, en México se desarrollaron disputas por el lugar de las civilizaciones azteca y maya en la formación nacional similares a los del caso brasileño. Sobre las opiniones de los historiadores mexicanos y el pasado indígena, consúltese KRAUZE, 2005.

33 Angelis, 1836 - 1837; vocabularios manuscritos de Pedro de Angelis, s.l.s.d., Archivo General de la Nación (Argentina), (en adelante AGN) "Colección Andrés Lamas", 2625 y 2626. 
clasificación, no comparte con el brasileño los dilemas de la integración del indígena en la nación.

La región del Río de la Plata y Argentina no se convertirían, hasta casi 1900, en una referencia para la historia y etnografía de América, posición que Brasil alcanzó con relativa facilidad ${ }^{34}$. Sin embargo, López entraría en el debate científico internacional antes que Varnhagen. A pesar de no lograr sus objetivos plenamente, un primer aspecto de sus intentos es digno de notar: su voluntad de pasar de la colección de vocabularios o el estudio de lenguas aisladas (como Angelis) al estudio de conjuntos de lenguas, analizadas en su aspecto histórico.

\section{EL QUECHUA Y EL TUPÍ EN LÓPEZ Y EN VARNHAGEN}

La estructura argumentativa de Las razas arias del Perú, de López, y de El origen turaniano, de Varnhagen, es similar. Los idiomas quechua y tupí no proporcionan todo el material. Se agregan datos históricos tomados de los cronistas coloniales, así como datos etnográficos, como mitología y religión, usos y costumbres, cultura material, arquitectura (en el caso inca) y caracteres físicos (sobre todo en el caso tupí). Los dos libros, se debe agregar, abordan la cuestión clave de la lingüística decimonónica (la genealogía), a partir de una hipótesis principal (son descendientes de lenguas del Este), que les permite, por fin, responder a un interrogante típico de las inquietudes antropológicas de la época (¿cuál es el grado de civilización de los denominados bárbaros o salvajes?) y otro histórico (¿cómo llegaron esas lenguas a América y cómo se impusieron?). A pesar de esas similitudes, el resultado son dos teorías distintas.

Para López, el quechua es un índice de la civilización de los pueblos americanos, que no dependerá del aporte del colonizador español. La extensión territorial original, aún verificada en 1870, lo hacen dominante en el continente: es "la lengua usual" de la provincia de Catamarca (Argentina) hasta Ecuador, del litoral del Pacífico hasta Paraguay, con hablantes presentes también en el Río de la Plata ${ }^{35}$. Si el quechua vive y es un idioma de origen mediterráneo (en el pelasgo, pueblo griego no helénico), vehículo de una civilización desarrollada, la consecuencia no puede ser otra que los pueblos de América del Sur bajo su influencia no son degradados, sino más bien todo lo contrario. De ahí que el sentido de la categoría de "raza", presente en el título, poco aparezca en su libro, pues es menos un concepto biológico (como en Varnhagen) que una referencia vaga a los pueblos o poblaciones americanas. En efecto, en un artículo publicado en el mismo año del libro, López afirma que "no hay error más contrario a la naturaleza humana, a la dignidad de la razón, que el de suponer que hay razas condenadas a no ser libres, aun cuando ellas lo quieran ser"36.

Para el autor brasileño, el índice lingüístico lleva a una caracterización distinta. No se puede decir que su método estuviera de acuerdo con las verificaciones morfo-sintácticas de los lingüistas de la época, pues se limita a etimologías aisladas, es decir, a

\footnotetext{
34 Rodrigues, 2008.

35 LÓPEZ, 1871a, p. 15.

36 López, 1871b, p. 456. Destacado en el original.
} 
semejanzas entre palabras o raíces. Otro problema es que, a diferencia de los idiomas orientales, el tupi era ágrafo, por lo cual las fuentes se limitaban a los informes de viajeros europeos y a las gramáticas escritas por portugueses y españoles (como José de Anchieta y Antonio Ruiz de Montoya) entre los siglos XVI y XVIII. Varnhagen no toma los elementos para sus comparaciones directamente de la literatura antigua de las lenguas europeas, africanas o asiáticas, sino más bien de gramáticas escritas por europeos, sobre todo del alemán, del griego, del fenicio, del egipcio, del asirio, del turco, del húngaro, del vasco y del árabe. A partir de esa bibliografía, se afirma que el tupí es semejante al fenicio (de familia semítica) y al egipcio (de familia desconocida), además de tener muchas palabras griegas (de origen indo-europeo). O sea, el tupí no podría ser clasificado, en un primer momento, en ninguna familia antigua. Varnhagen especula que el idioma indígena no es más que el cario, aunque casi nada se conociera sobre este pueblo. En realidad, en aquella época, todas las informaciones sobre los carios procedían de autores griegos antiguos, sobre todo de Heródoto (Varnhagen menciona también la "Ilíada", de Homero, y al historiador Tucídides), que los describían como guerreros y navegadores, que se habían aliado con los fenicios, que estuvieron presentes en Grecia y fueron esclavos de los faraones. Como pueblo asiático con tales características, los carios se beneficiaban, en las especulaciones de Varnhagen, de la teoría de la presencia fenicia en Brasil, de su carácter migratorio y de su poco desarrollo y civilización, pues no habían dejado testimonios de arte, arquitectura o literatura, solamente ejemplos de su espíritu belicoso. La hipótesis tenía tales dimensiones que Varnhagen continuó caracterizando a los carios como padres de los tupís y de los egipcios ${ }^{37}$. De esa forma, Varnhagen pudo clasificar a todos como "turanianos", a pesar de las dudas que cercaban a esa familia, que tuvo en el orientalista alemán radicado en Oxford Friedrich Max Müller a su más grande defensor.

Müller pretendió clasificar idiomas europeos y asiáticos no semíticos ni indo-europeos, como el finlandés, el húngaro, el turco, el egipcio y el vasco. Müller y Christian Bunsen propusieron, en una especular elaboración del modelo "ario", la existencia de una familia "turaniana", también oriunda del Cáucaso ${ }^{38}$. Al contrario de López, que claramente expresa su gratitud intelectual con Müller, Varnhagen no menciona nunca al famoso orientalista. Es probable que se haya inspirado también en otros autores que menciona, como los egiptólogos Bunsen, Brugsch, John Gardner Wilkinson y Henry Tattam, y el asiriólogo Julius Oppert.

En efecto, los turanianos no hacen buena figura. Si los descendientes egipcios de los carios dejaron su estado salvaje, lo mismo no ocurre con los tupís. Con ayuda de la etnografía, Varnhagen describe una raza degradada: de tipo físico mongol, brutal en sus conquistas e intolerante con los otros pueblos nativos. Todavía, y de acuerdo con la tensión resultante de que esos salvajes formaban parte de la primera época de la historia de Brasil y un objeto que el libro valoraba científicamente, el tupí de Varnhagen no perdía uno de los atributos favorables del abordaje "filantrópico" del

\footnotetext{
37 Ibídem, p. 143.

38 Bunsen, 1854; Müller, 1854. La popularización de la categoría turaniana se debe a Müller, 1861(López se refiere a ese libro en particular).
} 
indigenismo brasileño: su impresionante extensión territorial. Los tupís dominaban todo el Brasil y Paraguay, y parte de Uruguay y de Argentina. Además, el Caribe, un dialecto suyo, estaba extendido por casi todas las Antillas y América Central.

\section{PERSPECTIVAS POLÍTICAS DE LÓPEZ Y DE VARNHAGEN}

Los dos libros presentan contrastes también en sus apropiaciones del paradigma orientalista. A pesar de que el resultado no deja de alinearse, en términos generales, con algunos trazos verificados en Europa, la supervivencia del quechua y del tupí colocaba distintos problemas políticos e intelectuales.

Ambos autores se declaraban, desde el punto de vista científico, como americanistas. La perspectiva del americanismo no era brillante, por más que ambos escribieran en francés, publicaran en Europa y mantuvieran contactos con orientalistas. Las razas arias fue financiado por el presidente de la Confederación Argentina (Justo José de Urquiza). Parte de los fondos fueron utilizados para pagar la estadía del egiptólogo Gastón Maspero en Montevideo, donde vivía el autor argentino, para ayudar en la escritura de la obra. El origen turaniano fue publicado en Viena, donde Varnhagen era representante diplomático, y expresó el interés que el americanismo despertaba en Europa, al afirmar que la crítica a su teoría por parte de los creadores de la lingüística sería una buena ayuda que instruiría a los americanos y aumentaría la gloria de los europeos.

Así, los Orientalistas vendrán a ayudar a los Americanistas, y los Americanistas se tornarán a su turno Orientalistas; y unos y otros no dejarán de ganar, viendo aumentar el número de sus alumnos y el horizonte de sus investigaciones ${ }^{39}$.

Al contrario de Varnhagen, que buscaba insertar en el orientalismo el americanismo, desvelando la posición inferior de éste, López distinguía el americanismo por vías de un Nuevo Mundo de valor lingüístico y civilizador, incluso en comparación con Europa. La construcción de una estrategia discursiva que involucrara una perspectiva institucional e intelectual para el sabio americano se dirigía al centro de la ciencia europea, pero con argumentos arcaicos: la lengua de los incas era bella y simple. El criterio estético clásico que marcara el estudio de las lenguas hasta el surgimiento de la lingüística -la gramática como "arte" normativo y ejemplar- se imponía, entrando en el análisis objetivo. López, en otras palabras, admiraba el quechua.

La manera sobria e ingeniosa de la cual se deducen las formas gramaticales, la perfección de un sistema de declinación y de conjugación donde todo es uniforme y regular, el ordenamiento tan simple a la vez, y tan sabio de toda la frase, todo sorprende y alegra el espíritu. No están más las complicaciones y las irregularidades necesarias de nuestras lenguas donde las palabras no presentan más que restos de raíces y de flexiones usadas unas sobre las otras con un roce continuo, como guijarros rodando por las olas, edificios sabios y misteriosos construidos con las ruinas de edificios más antiguos

39 Varnhagen, 1876, p. XII. 
y en los cuales sólo el ojo ejercitado del filólogo puede reconocer el origen y la forma primitiva de los materiales. En el quechua, por más larga que sea la palabra, la raíz principal siempre sobresale entre las partículas que lo envuelven y le hacen cortejo, como un diamante hábilmente encerrado por la mano del orfebre se destaca en medio de un círculo de oro y perlas que lo rodea ${ }^{40}$.

El discurso clasicista basado en la armonía y en la regularidad creada por la genialidad reforzaba el vínculo del quechua, descendiente del pelasgo, con la grandiosidad helénica.

Los tupís no tenían la misma suerte. Conquistadores míticos e históricos, etapa del pasado brasileño, eran, entretanto, plenamente orientales, en una deriva casi semítica por la proximidad de los fenicios y egipcios. En suma, extranjeros. Lo probaba una lengua que "no tiene más de americano que el portugués, el español o el inglés". ${ }^{41}$ Además, no eran civilizados. La crueldad e intolerancia con que habían tratado a los nativos conquistados, configuraban, además, un aspecto de la relación entre pasado, presente y futuro de su proyecto historiográfico: "el día de la expiación no podría dejar de llegar, y llegó. Cristóbal Colón y Pedr' Álvares [sic] Cabral fueron los mensajeros"42. La conquista marcaba una nueva etapa de la historia del continente, que en un discurso ya influenciado por el darwinismo, podría ser entendida bajo un carácter evolutivo.

Todavía, las contradicciones de ese discurso no desaparecían, pues al no cuestionar la conquista, Varnhagen rebajaba no solamente a los cario-tupís, sino también, indirectamente, a los europeos. En realidad, Varnhagen percibía que la conquista no podría ser fácilmente dejada de lado como hecho perturbador. En la polémica con el historiador João Francisco Lisboa, la metáfora de los normandos era explicada como elevación de los tupís: "lejos de despreciar a los Indígenas yo los consideré siempre, comparándoles e igualándoles a lo que era la raza blanca, cuando bárbara o salvaje". Los tupís no eran una anomalía. Sin embargo, el rescate no era una redención (a pesar de implícitamente rechazar el determinismo racial), y curiosamente llevaba a un rebajamiento de los blancos: "creo que no eran mejores los europeos (empezando por los Germanos de que procedo) ni los asiáticos, cuando eran bárbaros y salvajes" ${ }^{43}$. Al fin y al cabo, tupís y europeos eran todos invasores, lo que concordaba con la historia universal, en la cual la expansión de los pueblos indo-europeos era un modelo.

El orientalismo de López, libre de las angustias y disputas indigenistas, podía mirar a los Andes como el Cáucaso de América. Su perspectiva se distancia de la de Sarmiento, así como de la de los orientalistas literarios a la Said, y se aproxima a la indomanía del pequeño grupo de lingüistas británicos de principios del siglo XIX, que tenía una mirada semejante a la de algunos románticos alemanes, y cuyo último representante en aquel campo quizás haya sido Müller ${ }^{44}$ - principal fuente de López. A pesar de reforzar el vínculo entre lengua y raza, Müller fue un abogado de la her-

\footnotetext{
40 LÓPEZ, $1871 \mathrm{a}$, p. 16.

41 Varnhagen, 1876, p. 109.

42 Ibídem, p. 107. Varnhagen se refiere a Pedro Álvares y utilizamos el sic para indicar el error.

43 Varnhagen, 1867 , p. 26. El padre de Varnhagen era alemán.

44 Trautmann, 1997, pp. 62-98.
} 
mandad de los pueblos arios, europeos y asiáticos. La historia antigua de India podía ser resumida como la conquista de un amplio territorio por un pueblo civilizado que vino de las montañas del Cáucaso. En el sur, adoptaron el idioma local, haciendo comprensible y aceptable su cultura superior respecto de los conquistados. El resultado fue la manutención y el desarrollo de la civilización en India. Eso imponía una lección moral para el imperio británico: asimilar a los indios arios con base en la fraternidad pacifica, como si fueran aliados de la política imperial ${ }^{45}$. La raza no era un destino, tal como lo creía el racismo científico.

Algo semejante hicieron los peruanos en América. En la teoría lingüística de López resulta poco relevante la categoría racial, que por esa época dominaba las ciencias sociales y naturales. Es nítida, además, la condena de la forma en que los españoles conquistaron América. Todavía, el paternalismo imperial inherente a la propuesta de Müller no está presente en el libro de López, ni, aparentemente, en otras producciones del historiador argentino. López tuvo elementos para tratar del asunto indígena como problema político real, ya que desde la década de 1830 Buenos Aires sufría los constantes "malones" (rápido ataque a caballo) de mapuches, tehuelches y ranqueles, y en las décadas de 1860 y 1870 crece el debate público sobre una solución para esas incursiones. Su alejamiento de la política argentina por haber sido un vocero del partido (derrotado) que en Buenos Aires defendía el compromiso de la provincia con un gobierno de unión nacional bajo una constitución que terminara con la autonomía provincial (representados en aquel momento por Urquiza), y un segundo exilio en Montevideo, que parece haberlo impactado bastante ${ }^{46}$, en donde se dedicó al derecho, la cátedra y el libro sobre el quechua, pueden explicar la ausencia de una perspectiva política clara. Otra hipótesis caracteriza a López como un moderado, sea por su intento de conciliar el historicismo romántico con la tradición clásica en la década de $1840^{47}$, o bien por su pensamiento político y económico de la década de 1870 que rechazaba tanto las medidas democráticas como también el libre comercio ${ }^{48}$. En efecto, López resalta las cualidades moderadas del antiguo Perú:

No sé hasta qué punto nosotros estamos autorizados a calificar como despótico el gobierno de los Incas. Las tradiciones que aún existen nos muestran que la voluntad del soberano se encontraba limitada por un ritual de corte y por una especie de iniciación casi masónica cuyas reglas y fórmulas sacramentales garantizan el derecho de los diversos cuerpos del Estado y aquellos de los particulares ${ }^{49}$.

López destaca en secuencia la protección a la propiedad privada y las escuelas para la nobleza, la vigilancia de la educación por el gobierno, y la sacramentación del casamiento. ¿Le proveían los Incas, de esta manera, un modelo que contrastaba con el de su desunida nación, dividida entre la Confederación y el Estado de Buenos Aires, desunión que le costó el exilio? Al final, el orientalismo anterior de Sarmiento, por

45 Ibídem, 1997, pp. 172-181.

46 LetTIERI, 1995, pp. 27-50.

47 Romero, 1943.

48 Chiaramonte, 1971; Lettieri, 1995.

49 LÓPEZ, 1871a, p. 307. 
ejemplo, ya involucraba a los indígenas, como destaca Axel Gasquet ${ }^{50}$-aunque para condenar a los nativos de las pampas.

La identificación de un discurso político gana densidad con el aporte del ensayo sobre "Lingüística y política orgánica", del mismo año en que imprime su libro, en el cual se establece una división entre las lenguas inorgánicas y las orgánicas. En las primeras, llamadas también polisintéticas, que serían anteriores a las segundas, existe una plena identidad entre sonido (o sílaba) y palabra, y sólo existen palabras hechas por una sílaba. Las palabras no se forman por asociación, y la asociación de las palabras es mecánica. Son, por lo tanto, inertes, así como el discurso. En las lenguas orgánicas, las palabras son resultados de asociaciones de elementos distintos (la raíz y la flexión), que hacen que la palabra cambie y gane vida. Conforme la flexión, presentan características de tiempo, persona, modo y número. La lengua pasa a ser un organismo vivo. Esa ley básica de la lingüística vale igualmente para los pueblos: "lo que es cierto de la lengua lo es de la vida social" ${ }^{51}$. Los pueblos que hablan lenguas inorgánicas, según su razonamiento, tienen un discurso limitado por la pobreza de las palabras y frases. Por lo tanto, la idea de libertad no se desarrolla y los individuos no consiguen la madurez y la creatividad para el auto-gobierno. La sociedad es un "conjunto de individualidades iguales, agrupadas en masa" ${ }^{52}$, sin divergencia de opiniones. En fin: es mediocre. Resulta, concluye el autor, que todo discurso de libertad escandaliza y es punido como un crimen.

Ese determinismo choca con la afirmación de López sobre la fragilidad del criterio racial. Al fin y al cabo, los chinos y los indios se liberan únicamente cuando migran y abandonan sus lenguas natales, por lo que pasan a amar la libertad y se civilizan ${ }^{53}$. En contraste, los argentinos, sin embargo, a pesar de que se inscribían en una tradición política despótica y que criminalizaban la opinión, hablaban un idioma orgánico. El camino de los argentinos no era el exilio, como el de los chinos (aunque López comente que la sociedad argentina era un poco china), sino una fidelidad a sus orígenes: "lo que nosotros necesitamos pues para ser libres es que nos dejen declinar y conjugar nuestra lengua política" ${ }^{54}$.

En ese modelo, los peruanos se quedaban en un estado semejante a los argentinos y españoles, y mejor que indios y chinos. Todavía, la ley de las lenguas inorgánicasorgánicas, que en Las razas arias se expresaba por la caracterización del quechua como una lengua aria aglutinante ${ }^{55}$, era una apropiación heterodoxa de la otra forma de clasificación de la lingüística, que, a partir de la morfología definía tres tipos de idiomas: los isolantes, en los cuales la palabra es formada por una y apenas una raíz; los aglutinantes (o polisintéticos), cuyas palabras son compuestas por dos o más raíces, en un proceso mecánico; y los fusionantes (o flexionales), que tendrían la capacidad de cambiar el sentido de las palabras mezclando a las raíces uno o más segmentos (afijos), de un modo orgánico. El primer propulsor de esa clasificación, Wilhelm von

\footnotetext{
50 GASQuet, 2007, pp. 16-17 y 50.

51 LÓPEZ, 1871 b, pp. 447.

52 Ibídem, p. 450.

53 LÓPeZ, 1871 b, p. 673.

54 Ibídem, p. 455. El destacado es de López.

55 López, 1871a, p. 21.
} 
Humboldt creía que todas las lenguas utilizaban al menos dos de los procesos, pero sólo uno era dominante. Se desprendía de su teoría que existían idiomas que habían pasado de isolantes a aglutinantes, y otros de aglutinantes a flexionales ${ }^{56}$.

Lo que estaba insinuado en Humboldt fue aclarado por Müller, quien afirmó el carácter evolutivo del pasaje de etapas simples a complejas, lo que guarda una analogía con la idea spenceriana de evolución, del homogéneo al heterogéneo ${ }^{57}$. En la divulgación de la teoría morfológica, una cuarta categoría fue adicionada: las lenguas polisintéticas, compuestas por la familia de idiomas americanos. En este proceso, una variación de la aglutinación, las palabras-raíces compuestas en un nuevo vocablo pierden toda su autonomía ${ }^{58}$. Müller también afirmó que el sánscrito (un idioma flexional) pasaba por un período de estructura más sencilla antes de completar su evolución. En efecto, cuando López creó el concepto de "lengua aria aglutinante" estaba aprovechando la posibilidad de que los idiomas experimentan transiciones, de manera que intentaba evitar el peligro del evolucionismo spenceriano que él recusaba para las razas. El quechua, de esa manera, estaba en un grado más bajo que las lenguas orgánicas (flexionales), pero su origen ario dejaba insinuado que el proceso de desarrollo histórico no había sido completado, tal como el desarrollo político de un imperio que, si bien protegía la propiedad, la educación y la moral, no era de ciudadanos libres. Por fin, y siempre de acuerdo con el posible espejo argentino, el idioma español en América no garantizaba, por sí solo, la civilización política (el dominio de la plena libertad). El Perú incaico no era, en esos términos, muy distinto de la Argentina. Para Elías Palti, las formulaciones de López revelan un rechazo a un organicismo genético, por el cual no importaba la cuestión de los orígenes ${ }^{59}$. Frente a la lectura que López hizo de Müller y la relación entre Las razas arias y "Lingüística y política orgánica", resulta más bien que el paradigma genético dominante en la época no era ajeno a sus formulaciones.

A su modo, el orientalismo de Varnhagen encontraba claros condicionantes políticos. El origen asiático cario tentaba resolver tanto los problemas políticos de la integración de los indígenas al Imperio, cuanto buscar en Europa la legitimación científica (que, al fin, no encontró) ausente en un Brasil en el cual los estudios indígenas estaban por demás ligados a una orientación política que no era la suya.

La perspectiva de Varnhagen se aproxima a las características destacadas por Hobsbawm sobre el concepto liberal de nación de principios del siglo XIX, vinculado históricamente a un Estado viable, esto es, con economía, ejército y población suficientes para mantener su soberanía, lo que se concretizaba por su capacidad para la conquista (lo que Hobsbawm llama "principio del umbral" ${ }^{00}$ ). La monarquía brasileña era descendiente de unos de los reinos más antiguos de Europa, cuya tradición de conquistas ultramarinas era vindicada en las victorias en las guerras en contra de la Argentina (1825-1828), Rosas (1851-1852) y el Paraguay (1864-1870). Los tupís, al contrario, eran indolentes y nómadas, incapaces de construir un orden que produ-

\footnotetext{
56 Humboldt, 1988, pp. 100-108.

57 SPENCER, 1891.

58 MÜLLER, 1861, pp. 263-73 y pp. 312-328.

59 Palti, 2009, pp. 123-130.

60 Hobsbawm, 1998, p. 40.
} 
jera riqueza y controlara un territorio definido. Su estado político (sin un gobierno unificado) tampoco era envidiable: "la grande nación de los Tupís" estaba desde la llegada en América "fraccionada en bandos bajo los nombres de Tupi-n'ambás, Tupin'aês, Tupi-n'ikis, Carijós, Guaranís y muchos otros" ${ }^{1}$. En un paralelo contrastante, Varnhagen comenta que los tupí-caribes solo fueron arrestados por "las grandes nacionalidades organizadas de Perú y de México". ${ }^{62}$ En otras palabras, los tupís eran meramente una nacionalidad bajo el punto de vista étnico-lingüístico; los peruanos y aztecas alcanzaron el estadio de naciones políticas -tenían su propria cultura y también un Estado, que fue precisamente lo que permitió que constituyeran, a través de conquistas militares, sus propios imperios.

Ese vínculo conceptual con la nación liberal decimonónica se sumaba a cierta noción iluminista de clasificación de los pueblos de acuerdo con su organización social. Varnhagen destaca como condicionante de la manutención del estado salvaje de los tupís las condiciones plenas que América ofrecía para el hábito de la caza ${ }^{63}$. El vínculo entre el nomadismo, la incapacidad de organización política y el primitivismo estaba presente en varias referencias intelectuales del siglo XVIII, como William Robertson, Adam Smith, Montesquieu y Condorcet ${ }^{64}$. La estructura aglutinante hacía del tupí un idioma adecuado para un pueblo fraccionado en bandos que se esparcía por las áreas bajas de América, cuyos inmensos ríos y florestas le suministraban lo poco que sus necesidades materiales primitivas requerían -al contrario de las sociedades "organizadas" de las montañas andinas, donde se pastoreaba y se cultivaban los campos. Se puede añadir que la imagen del árbol no era la única metáfora de mudanza histórica de la lingüística que, según Alter, influenció el discurso de otras ciencias; también estaba la de la escalera ${ }^{65}$. En efecto, la teoría morfológica y la Ilustración convergían en difundir procesos hechos por etapas ascendentes que se materializaban en las lenguas y en los pueblos orientales y americanos.

\section{5. ¿VARNHAGEN LECTOR DE LÓPEZ?}

No cabe duda de que los dos historiadores estaban bien informados sobre los debates lingüísticos en Europa. Y si el argumento de que sus teorías daban sentido histórico para dilemas políticos de Argentina y Brasil es verdadero, queda el interrogante sobre la relación entre los dos autores.

A falta de referencias directas entre ellos, quedan algunos indicios de que la publicación de dos libros bastante parecidos y originales no fue una coincidencia. Es posible que Varnhagen haya recibido un estímulo más para publicar su heterodoxa

\footnotetext{
61 VARNHAGEN, 1876, p. 1.

62 Ibídem, p. 22.

63 Ibídem, p. 102.

64 Robertson, 1840, pp. 1-5. Véase también: CAnnan, 1896, pp. 14-25; SMith, 1794, p. 1; CONDORCET, 1795, pp. 30-72; Montesquieu, 1821, p. 66. Axel Gasquet nota que Sarmiento había, precisamente, recibido la influencia de los fisiócratas franceses del siglo XVIII en su apreciación negativa del nomadismo de los árabes y de la vida pastoril de los gauchos argentinos (GASQUET, 2007, pp. 82-83).

65 Alter, 1999.
} 
teoría al entrar en contacto con el libro de López, del cual tenía una copia. No existen comentarios o notas suyas acerca de Las razas arias. Todavía, los temas americanistas le interesaban, como demuestra su colección de libros sobre el Perú, en donde, además, Varnhagen vivió como representante de Brasil, entre 1863 y 1867. En una correspondencia al monarca, de 1863, Varnhagen agradece la oportunidad de conocer los Andes, en los cuales encontró indígenas "semicivilizados" y que sólo hablaban el quechua ${ }^{66}$. En otra correspondencia al monarca, de 1865, el autor comenta que los paraguayos eran más guaraníes que hispano-americanos, lo que los haría distantes de los argentinos ${ }^{67}$. En un informe al ministro de relaciones exteriores del mismo año, el historiador proponía que al fin de la guerra con Paraguay, dicho país debía ser anexado por Brasi1 ${ }^{68}$. Aparte de Argentina, Chile (sobre los cuales no comenta desde ese punto de vista) y Uruguay (cuya población consideraba mitad argentina, mitad brasileña), el panorama sudamericano comportaba una geopolítica de fondo indígena, dividida en zonas quechua y tupí (en la cual el Paraguay se encontraba).

Si las lecturas sobre el quechua y la historia inca reforzaran sus impresiones de diplomático, es posible que la lectura de Las razas arias, en algún momento entre 1868 y 1875, cuando escribe El origen turaniano, haya representado un modelo de investigación sobre una historia antigua de la singularidad brasileña en el continente. Tampoco es improbable que, a pesar del escándalo que pudiera causar la vinculación de los quechuas con los arios, la amplia circulación de un libro publicado por un autor desconocido en Europa, en parte publicado en América, haya llamado la atención de Varnhagen. El libro de López no era ajeno a los brasileños: el catalogo de la prestigiosa librería Garnier de Rio de Janeiro de la década de 1880 presentaba Las razas arias $^{69}$. Y, al fin y al cabo, López pasó a ser considerado un americanista digno de alguna consideración, como muestran las cartas que recibió de dos de los más famosos estudiosos del quechua del período, el inglés Clement Markham ${ }^{70}$ y el suizo Johann Jakob von Tschudi.

Es interesante notar, aunque de forma especulativa, que Tschudi también era un diplomático, enviado a Viena en 1866, dos años antes que Varnhagen. El brasileño, que murió en aquella ciudad en 1878, ganó del suizo un ejemplar autografiado de su traducción de un poema inca. El Ollanta ${ }^{71}$ fue publicado en 1875 , y dos años después Tschudi escribió desde Viena a López ${ }^{72}$, cuando confesó que recién había tenido contacto con Las razas arias. De su parte, y también en 1875, Varnhagen comunicaría entusiasmado a Don Pedro II que finalmente, después de décadas intrigado con la cuestión del origen de los nativos brasileños, había resuelto el enigma ${ }^{73}$. De esa manera, es posible que al preparar el material para su traducción, Tschudi haya

66 VARnhagen, 1961, pp. 287-288.

67 Ibídem, p. 297.

68 Ibídem, p. 296.

69 Garnier, p. 139.

70 Correspondencia de C. Markham a V. F. López, 3-VIII-1883. AGN, "Colección Carlos Casavalle", 2291.

71 TsChudi, 1875.

72 Correspondencia de J. J. von Tschudi a V. F. López, 18-XII-1877. AGN, “Colección Carlos Casavalle”, 2296.

73 Varnhagen, 1961, p. 434. 
descubierto el libro de López y, por su contacto con Varnhagen, le hubiera llamado la atención el singular estudio del argentino, quien lo estimuló a seguir en el paradigma de una migración oriental.

\section{CONCLUSIÓN}

Para López el Oriente es seductor como un parámetro de un proceso civilizador presente en América. En Varnhagen la ascendencia turaniana insinúa una América cerca de África y del Levante, que convierte al historiador en un orientalista de otro tipo, más parecido al modelo del comentarista al servicio de los imperios europeos, aunque a veces seducido por la noción de un Oriente inmanente a la nación. Todavía, cabe resaltar un punto de contacto en un último aspecto, que revela las consecuencias imprevistas de los orientalismos del siglo XIX, si los comprendemos más allá de la perspectiva de Said. Periféricos que estaban en el universo científico mundial, Las razas arias y El origen turaniano rompían, a través de la historia indígena americana y sus fuentes orientales, la unidad de Occidente y su bipolaridad frente al Oriente. Si las teorías fueran verdaderas, el naciente americanismo haría, en López, que América y Europa tuvieran orígenes en Asia, y, en Varnhagen, que América fuera el par rebajado de Europa -por obra de Asia. En cualquiera de los dos casos, la historia universal tendría que ser rescrita. El americanismo, a partir de la década de 1870, rechazaría toda teoría de una travesía atlántica de los primeros indígenas, aunque el parámetro lingüístico se mantendría. En ese sentido, las investigaciones orientalistas de López y de Varnhagen no resultaran tan exóticas o infructuosas.

\section{REFERENCIAS BILIOGRÁFICAS}

Alegre, Manoel de Araújo Porto - Barbosa, Januário da Cunha

1839 "Relatório sobre a inscrição da Gávea mandada examinar pelo Instituto Histórico e Geográfico Brasileiro". Revista do Instituto Histórico e Geográfico Brasileiro. Rio de Janeiro, vol. I, $\mathrm{n}^{\mathrm{o}}$ 2, pp. 77-81.

Altamirano, Carlos

1994 "El orientalismo y la idea de despotismo en Facundo". Boletín del Instituto de Historia Argentina y Americana Dr. Emilio Ravignani. Buenos Aires, nº 9, pp. 7-19.

Alter, Stephen

1999 Darwinism and the linguistic image. Baltimore y London. The John Hopkins University Press.

AmANTE, Adriana

2005 "Brasil, el oriente de América". En BatTicuore - Gallo - Myers (comp.). Resonancias románticas: ensayos sobre historia de la cultura argentina (1820-1890). Buenos Aires. Eudeba, pp. 181-197.

Angelis, Pedro de

1836-1837 Colección de obras y documentos relativos a la historia antigua y moderna de las provincias del Río de la Plata. 7 vols. Buenos Aires. Imprenta del Estado. 
AURENCHE, Marie-Laure

2003 "Découvir l'Égypte sans quitter Paris: l'itineraire du Magazin Pittoresque à Deux Sous (1833-1870)". Romantisme. Paris, vol. 33, nº 120, pp. 47-55.

Bunsen, Christian Karl Josias von

1854 Outlines of the philosophy of universal history, applied to language and religion. 2 vol. London. Longman, Brown, Green, and Longmans.

Cannan, Edwin (comp.)

1896 Lectures on justice, police, revenue and arms delivered in the University of Glasgow by Adam Smith reported by a student in 1763. Oxford. Clarendon Press.

Casanova, Rosa

1994 "Imaginando el pasado: el mito de las ruinas de Palenque (1784-1813)". En GuerrA

- QuiJada (coord.), Imaginar la nación. Hamburgo. Asociación de Historiadores Latinoamericanistas Europeos, vol. 2, pp. 35-63.

Chiaramonte, José Carlos

1971 Nacionalismo y liberalismo económicos en Argentina, 1860-1880. Buenos Aires. Hachette.

Christo, Maraliz Vieira

2009 "A pintura de história no Brasil do século XIX: panorama introdutório". Arbor: ciencia, pensamiento, cultura. Madrid, vol. 185, n 740, pp. 1147-1168.

Cicerchia, Ricardo

2004 "Journey to the centre of the earth: Domingo Faustino Sarmiento, a man of letters in Algeria”. Journal of Latin American Studies. Cambridge, nº 36, pp. 665-686.

Colombi, Beatriz

2005 "Sarmiento: orientalismo, españolada y prisma europeo". En BATTiCuORE - GAllo Myers (comp.), Resonancias románticas: ensayos sobre historia de la cultura argentina (1820-1890). Buenos Aires. Eudeba, pp. 211-222.

CONDORCET, Nicholas de

1795 Esquisse d'un tableau historique des progrès de l'esprit humain. Paris. Agasse.

Florescano, Enrique

2005 Imágenes de la patria a través de los siglos. México D.F. Taurus.

FrançA, Ernesto Ferreira

1859 Crestomatia da língua brasílica. Leipzig. F. A. Brockhaus.

Freitas, Marcus Vinicius de

2002 Charles Frederick Hartt, um naturalista no Império de Pedro II. Belo Horizonte. Editora da UFMG.

GARNIER, Baptiste-Louis

S. f. Catalogue de la librairie de B.-L. Garnier n ${ }^{\circ}$ 20. Rio de Janeiro.

GASQuET, Axel

2007 Oriente al sur. El orientalismo literario argentino de Esteban Echeverría a Roberto Arlt. Buenos Aires. Eudeba.

HobsBawm, Eric

1991 La era de la revolución, 1789-1848. Barcelona. Labor.

1998 Naciones y nacionalismo desde 1780. Barcelona. Crítica. 
Humboldt, Wilhelm von

1988 The diversity of human language-structure and its influence on the mental development of mankind [1836]. Cambridge. Cambridge University Press.

Junco, José Álvarez

2003 Mater Dolorosa. La idea de España en el siglo XIX. Madrid. Taurus. 7 a edición.

Kodama, Kaori

2009 Os índios no Império do Brasil: a etnografia do IHGB entre as décadas de 1840 e 1860. São Paulo. Rio de Janeiro. EDUSP. Fiocruz.

KrAUZE, Enrique

2005 La presencia del pasado. Barcelona. Tusquets.

LANGER, Johnni

2002 "A cidade perdida da Bahia: mito e arqueologia no Brasil império". Revista Brasileira de História. São Paulo, vol. 22, n 43, pp. 127-152.

LETTIERI, Alberto Rodolfo

1995 Vicente Fidel López: la construcción histórico-política de un liberalismo conservador. Buenos Aires. Biblos. Fundación Simón Rodríguez.

López, Vicente Fidel

1871a Les races aryennes du Pérou: leur langue, leur religion, leur histoire. Paris. Librairie A. Franck. Montevideo. Chez l'Auteur.

1871 b "Lingüística y política orgánica". Revista del Río de La Plata: periódico mensual de historia y literatura de América. Buenos Aires, vol. I, $\mathrm{n}^{\circ} 3$ y no 4, pp. 444-461 y pp. 670-690.

MaCHADO, Maria Helena P. T.

2002 "Os tupis e a Turânia: hipóteses sobre a origem do homem e da civilização nas Américas na segunda metade do XIX e primeiras décadas do XX". Revista do Museu de Arqueologia e Etnologia. São Paulo, n 12, pp. 3-16.

Matos, Raimundo José da Cunha

1863 "Dissertação acerca do sistema de escrever a história antiga e moderna do Império do Brasil". Revista do Instituto Histórico e Geográfico Brasileiro. Rio de Janeiro, vol. 26, pp. 121-145.

Montesquieu, Charles-Louis Secondat de

182 Del espíritu de las leyes [1748]. Vol. II. Madrid. Casa de Rosa.

MüLLER, Friedrich Max

1854 Letter to Chevalier Bunsen on the classification of the Turanian languages. Londres. Longman, Brown, Green, and Longmans.

1861 Lectures on the science of language. Londres. Longman, Green, Longman, and Roberts.

OlENDER, Maurice

1992 The languages of Paradise: race, religion and philology in the nineteenth century. Cambridge. Harvard University Press.

Palti, Elías José

2000 "La Historia de Belgrano de Mitre y la problemática concepción de un pasado nacional". Boletín del Instituto de Historia Argentina y Americana Dr. Emilio Ravignani. Buenos Aires, $n^{\circ}$ 21, pp. 75-115.

2009 El momento romántico: nación, historia y lenguajes políticos en la Argentina del siglo $X I X$. Buenos Aires. Eudeba. 
RAMírez, Fausto

2003a “El proyecto artístico en la Restauración de la República". En VV.AA., Los pinceles de la historia. La fabricación del Estado (1864-1910). México D.F. Consejo Nacional para la Cultura y las Artes - Instituto Nacional de Bellas Artes, pp. 54-89.

2003b "México a través de los siglos (1881-1910): la pintura de historia durante el Porfiriato". En VV.AA., Los pinceles de la historia. La fabricación del Estado (18641910). México D.F. Consejo Nacional para la Cultura y las Artes - Instituto Nacional de Bellas Artes, pp. 110-145.

Reyero, Carlos

2004 "Pasivos, exóticos, vencidos, víctimas. El indígena americano en

la cultura oficial española del siglo XIX”. Revista de Indias. Madrid, vol. 64, n 232, pp. 721-748.

Ribeiro, Duarte da Ponte

2012 "Memória sobre a República do México, por Duarte da Ponte Ribeiro, encarregado de negocios do Império do Brasil (1835)". Cadernos do CHDD. Rio de Janeiro, $\mathrm{n}^{\mathrm{o}} 21$, 2012, pp. 101-131.

Riviale, Pascal

1999 "La science en marche au pas cadencé: les recherches archéologiques et anthropologiques durant l'intervention française au Mexique (1862-1867)". Journal de la Société des Américanistes. Paris, vol. 85, pp. 307-341.

ROBERTSON, William

1840 Historia de la América [1777]. Vol. IV. Barcelona. J. Oliveres y Gavarró.

Rodrigues, João Paulo Coelho de Souza

2008 "Tupifilia internacional: tupi, cientistas e viajantes no século XIX”. En LiMA - CARMO (eds.), História social da língua nacional. Rio de Janeiro. Fundação Casa de Rui Barbosa, pp. 327-351.

Roldán, Darío

2005 "Sarmiento y el viaje a Argelia: entre el inmovilismo y la utopía social". En BATTICUORE - GAllo - Myers (comp.), Resonancias románticas: ensayos sobre historia de la cultura argentina (1820-1890). Buenos Aires. Eudeba, pp. 199-210.

Romero, José Luís

1943 "Estudio preliminar". En LóPEz, Memoria sobre los resultados generales que los pueblos antiguos han contribuido a la civilización de la humanidad. Buenos Aires. Nova, pp. 8-18.

SAID, Edward

1990 Orientalismo: o oriente como invenção do ocidente. São Paulo. Companhia das Letras.

SARMiento, Domingo Faustino

1867a "Libros en castellano para la América Del Sur". Ambas Américas. Revista de educación, bibliografía, agricultura. Nueva York, vol. I, no 1, pp. 46-55.

$1867 \mathrm{~b}$ "Bibliotecas populares". Ambas Américas. Revista de educación, bibliografia, agricultura. Nueva York, vol. I, nº 2, pp. 62-70.

Sмiтh, Adam

1794 Investigación de la naturaleza y causa de la riqueza de las naciones. Vol. IV. Valladolid. Oficina de Viuda e Hijos de Santander. 
SouzA, Guilherme Queiroz de

2010 A mentalidade de cruzada na conquista de México - Tenochtitlán (1519-1521). Tesis de Maestría en Historia. São João del Rei. Universidade Federal de São João del Rei.

SPENCER, Herbert

1891 "Progress: its law and cause" [1857]. En SPENCER, Essays: scientific, political and speculative. Vol. I. London. Williams and Norgate.

TAUB, Emmanuel

2008 Otredad, orientalismo e identidad. Nociones sobre la construcción de un otro oriental en la revista Caras y Caretas (1898-1918). Buenos Aires. Teseo.

Tschudi, Johann Jakob von

1875 Ollanta: ein altperuanisches drama aus der Kechuasprache. Viena. Karl Gerold's Sohn.

Trautmann, Thomas R.

1997 Aryans and British India. Los Angeles. University of California Press.

TuRIN, Rodrigo

2010 "Entre 'antigos' e 'selvagens': notas sobre o uso da comparação no IHGB". Revista de História. São Paulo, Edición especial, pp. 131-146.

VARnhagen, Francisco Adolfo de

1849 "Etnografia indígena: línguas, emigrações, e arqueologia. Padrões de mármore dos primeiros descobridores". Revista do Instituto Histórico e Geográfico Brasileiro. Rio de Janeiro, vol. 12, no 15 , pp. 366-377.

1854 História geral do Brasil. Vol. I. Madrid. Imprenta de V. Dominguez.

1851 "Memorial orgânico". Guanabara. Revista mensal, artística, científica e literária. Rio de Janeiro, vol. I, pp. 357-370 y pp. 382-402.

1867 Os índios bravos e o Sr. Lisboa, Timon $3^{\circ}$. Lima. Imprenta Liberal.

1876 L'origine touranienne des américains tupi-caribes et des anciens égyptiens montrée principalement par la philologie comparée: traces d'une ancienne migration en Amérique, invasion du Brésil par les tupis, etc. Viena. Faesy \& Frick.

1961 Correspondência ativa. Rio de Janeiro. INL/MEC. 